\title{
QT interval dispersion in obstructive sleep apnoea syndrome patients without hypertension
}

\author{
D. Dursunoglu*, N. Dursunoğlü\#, H. Evrengül*, S. Özkurt”, M. Kılıç*, \\ F. Fisekci\#, Ö. Kuru* and Ö. Delen\#
}

ABSTRACT: $Q T$ interval dispersion (QTd) reflects inhomogeneity of repolarisation. Delayed cardiac repolarisation leading to the prolongation of the QT interval is a well-characterised precursor of arrhythmias. Obstructive sleep apnoea syndrome (OSAS) can cause cardiovascular complications, such as arrhythmias, myocardial infarction, and systemic and pulmonary hypertension. The aim of this study was to assess QTd in OSAS patients without hypertension.

A total of 49 subjects without hypertension, diabetes mellitus, any cardiac or pulmonary diseases, or any hormonal, hepatic, renal or electrolyte disorders were referred for evaluation of OSAS. An overnight polysomnography and a standard 12-lead ECG were performed in each subject. According to the apnoea-hypopnoea index $(\mathrm{AHI})$, subjects were divided into control subjects $(A H I<5, n=20)$ and moderate-severe OSAS patients (AHI $\geqslant 15, n=29)$. QTd (defined as the difference between the maximum and minimum QT interval) and QT-corrected interval dispersion (QTcd) were calculated using Bazzet's formula.

In conclusion, the QTcd was significantly higher in OSAS patients $(56.1 \pm 9.3 \mathrm{~ms})$ than in controls $(36.3 \pm 4.5 \mathrm{~ms})$. A strong positive correlation was shown between QTcd and AHI. In addition, a significantly positive correlation was shown between $Q T c d$ and the desaturation index (DI). The AHI and DI were significantly related to $Q T c d$ as an independent variable using stepwise regression analysis.

The QT-corrected interval dispersion is increased in obstructive sleep apnoea syndrome patients without hypertension, and it may reflect obstructive sleep apnoea syndrome severity.

\section{KEYWORDS: Obstructive sleep apnoea syndrome, QT interval dispersion}

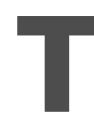
he variability in the QT interval duration between the different leads of a surface 12-lead ECG reflects local differences in recovery time of the myocardium $[1,2]$. In addition, QT interval dispersion (QTd) is increased in patients with a priori myocardial infarction, who have a susceptibility to ventricular tachyarrhythmias, most obviously via a reentry mechanism [3]. It has been suggested that increased QTd may be a marker of arrhythmic risk in patients with impaired left ventricular function [4].

Obstructive sleep apnoea syndrome (OSAS) is characterised by repetitive collapse of the upper airway during sleep [5]. The obstructive apnoeic event is associated with considerable breathing efforts against the totally or partially occluded upper airway. The apnoea is terminated by an arousal and heavy snoring as airflow is restored. Severity of OSAS is described according to the total number of apnoeas and hypopnoeas per hour of sleep, which is termed the apnoeahypopnoea index (AHI).

Cardiovascular disturbances are the most serious complications of OSAS. These complications include nocturnal arrhythmias [6], acute myocardial infarction [7], heart failure [8], stroke [9], and systemic [10, 11] and pulmonary hypertension [12]. All of these cardiovascular complications increase the morbidity and mortality of OSAS. Sleep apnoea is currently accepted as one of the identifiable causes of hypertension, as described in the JNC 7 report [13].

The aim of the present study was to assess QTd in OSAS patients without hypertension.

\section{METHODS}

Study population

Ninety-six subjects were admitted to a sleep clinic with nocturnal snoring and/or excessive
AFFILIATIONS

Depts of *Cardiology, and

\#Chest Disease, Pamukkale University Medical Faculty, Denizli, Turkey.

CORRESPONDENCE

D. Dursunoglu

Yunus Emre Mah. 6402 sk. №: 12 Kınıklı - Denizli

Turkey

Fax: 902582134922

E-mail: ddursunoglu@tnn.net/ ddursunoglu@pamukkale.edu.tr

Received:

June 072004

Accepted after revision:

December 232004 
daytime symptoms, and a detailed sleep and cardiovascular anamnesis of the patients was recorded. Sleep cycle, nutritional status, medications, alcohol usage and family anamnesis were also established. All patients were asked questions from the Epworth sleepiness scale (ESS) [14], and patients with high scores $(E S S \geqslant 10)$ were accepted into the sleep study.

A physical examination was performed on all subjects. Systolic (BPs) and diastolic (BPd) blood pressures were measured in the sitting position from the right arm using a sphygmomanometer (Erka, Bad Tölz, Germany), after $\geqslant 5$ min of rest. Heart rate per minute (HR) was measured in the sitting position, and the body mass index (BMI) of each patient was calculated as weight divided by height squared $\left(\mathrm{kg} \cdot \mathrm{m}^{-2}\right)$. After an overnight fast $(\geqslant 12 \mathrm{~h})$, routine biochemical parameters (e.g. blood glucose, lipids, urea, creatinine, electrolytes, hepatic enzymes) were analysed using commercial kits (Abbott Laboratories, Abbott Park, IL, USA) by an autoanalyser (Aeroset; Abbott Laboratories).

Pulmonary function tests (SensorMedics 2400; SensorMedics, Bilthoven, The Netherlands) and arterial blood gas analysis (ABL 30; Radiometer, Copenhagen, Denmark) were performed in all patients at rest. In the morning, a 12-lead surface ECG was taken from every subject: all were in sinus rhythm, and no subjects had intraventricular conduction delay or a prolonged QRS complex, which would thereby increase the QT interval. In addition, all of subjects underwent treadmill exercise testing, which was normal for each subject. None of the subjects was taking medications that could potentially prolong the QT interval.

To be eligible, none of the 96 subjects was permitted to suffer from: 1) any known cardiac or pulmonary disease; 2) hypertension (blood pressure $>140 / 90 \mathrm{mmHg}$ or taking antihypertensive therapy); 3) diabetes mellitus or impaired glucose tolerance (fasting blood glucose $>110 \mathrm{mg} \cdot \mathrm{dL}^{-1}$ or taking antidiabetic therapy); 4) angina pectoris; 5) bundle branch block, atrial fibrillation, any arrhythmias or fewer than six measurable leads in the resting ECG; 6) chronic renal or hepatic diseases (by both self-report and serum analysis); or 7) serum electrolytes imbalances.

\section{Polysomnography}

Polysomnography [15] was applied to all subjects during the diagnostic night. The portable, limited sleep study, performed with an Embletta device [16], consisted of the following: 1) nasal pressure detection using a nasal cannulae/pressuretransducer system, which recorded the square root of pressure as an index of flow; 2) thoraco-abdominal movement detection, via two piezoelectric belts; 3) finger pulse oximetry; and 4) body position detection.

An apnoea was defined as total obstruction of oronasal airflow for $\geqslant 10 \mathrm{~s}$, a hypopnoea was defined as a decrease of airflow of $\geqslant 50 \%$ and desaturations were accepted as a $\geqslant 4 \%$ decrease in oxygen saturation [17]. The desaturation index (DI) was identified as the number of oxygen desaturation events per hour of sleep. Subjects with an AHI $\geqslant 5$ were diagnosed as OSAS [18]. According to the AHI, subjects were divided into two groups: 1 ) control subjects ( $\mathrm{AHI}<5, \mathrm{n}=20$ ); and 2) patients with moderate-severe OSAS (AHI $\geqslant 15, n=29$ ). There were no mild OSAS (AHI 5-15) patients in the study population.

\section{Measurement of QT interval and dispersion}

In the morning, after $\geqslant 10$-min rest in the supine position, a 12lead ECG was recorded at a paper speed of $50 \mathrm{~mm} \cdot \mathrm{s}^{-1}$ on a sixchannel recorder. Two consecutive cycles were measured from each of the standard 12 leads and, subsequently, a mean QT was calculated from the two values. The QT intervals were manually measured from the onset of the QRS to the end of the T-wave, defined as the return to TP isoelectric baseline, by a tangential method [3]. Only monophasic well-defined T-waves were accepted for measurement. When U-waves were present, the QT was measured to the nadir of the curve between the $\mathrm{T}$ and $\mathrm{U}$ waves, with the aid of a tangent. If the end of the $\mathrm{T}$-wave could not be reliably determined, or if T-waves were isoelectric or of very low amplitude, the lead was not included in the analysis. A minimum of six leads, at leads three precordial, was required for inclusion in the study. The measurements were performed manually by an experienced observer blinded to the clinical data of the patients. The QTd was defined as the difference between the maximum and minimum QT values, and the mean value of two consecutive cycles was calculated. Bazett's formula was used to obtain HRcorrected (c) values of the QT intervals and dispersions [19], as follows:

$$
\mathrm{QT}_{\mathrm{c}}=\mathrm{QT} / \sqrt{ } \mathrm{RR}
$$

To estimate the intra-observer variability, two photocopies of a random sample of 10 ECGs were taken and the QT interval was measured again. The relative difference (mean absolute difference in percentage of mean measured value) was $1.5 \%$ for the QT interval and $4.2 \%$ for the QTd.

\section{Statistical analysis}

Results are presented as mean \pm SD and the Mann-Whitney Utest was used to compare the two groups. Stepwise regression analysis was used to identify possible determinants of QTcorrected interval dispersion (QT $\mathrm{cd}$ ). The correlations among QTcd and the variables of OSAS severity were investigated by Pearson correlation analysis. A p-value $<0.05$ was considered statistically significant.

\section{RESULTS}

A total of 27 males and 22 females were included the study. None of them was using alcohol and $45 \%$ of them smoked cigarettes. The mean ESS score of the study population was $16.8 \pm 6.1$ (range 10-24). Basic characteristics and QTcd of the moderate-severe OSAS patients and controls are shown in table 1 . There were no significant differences between moderate-severe OSAS patients and controls according to sex, age, $\mathrm{BMI}, \mathrm{BP}, \mathrm{BPd}$ and $\mathrm{HR}(\mathrm{p}>0.05)$. AHI and DI were significantly higher in moderate-severe OSAS patients than in controls $(\mathrm{p}<0.0001)$, although, in contrast, these patients had the lowest average and minimum nocturnal saturation of arterial oxygen $\left(\mathrm{Sa}, \mathrm{O}_{2} ; \mathrm{p}<0.0001\right)$. The percentage of sleep duration where $\mathrm{Sa}_{2} \mathrm{O}_{2}$ was $<90 \%$ was highest in the OSAS patients, whereas it was lowest in controls.

The QTcd was significantly higher in moderate-severe OSAS patients $(56.1 \pm 9.3 \mathrm{~ms})$ than in controls $(36.3 \pm 4.5 \mathrm{~ms}$; $\mathrm{p}<0.001)$. A strong positive correlation was shown between QTcd and AHI, reflecting the severity of OSAS $(\mathrm{p}<0.001$, $\mathrm{r}=0.954)$. Correlation between QTcd and AHI in OSAS patients 


\begin{tabular}{|c|c|c|c|}
\hline \multirow[t]{2}{*}{ TABLE 1} & \multicolumn{3}{|c|}{$\begin{array}{l}\text { Basic characteristics and QT-corrected interval } \\
\text { dispersion (QTcd) in moderate-severe obstructive } \\
\text { sleep apnoea syndrome (OSAS) patients and } \\
\text { controls }\end{array}$} \\
\hline & Controls $(\mathrm{AHI}<5)$ & OSAS $(A H I \geqslant 15)$ & p-value ${ }^{\#}$ \\
\hline Subjects $n$ & 20 & 29 & \\
\hline Male & $11(55)$ & $16(55)$ & NS \\
\hline Female & $9(45)$ & $13(45)$ & NS \\
\hline Age yrs & $45.0 \pm 4.6$ & $45.8 \pm 5.1$ & NS \\
\hline BMI $\mathrm{kg} \cdot \mathrm{m}^{-2}$ & $28.3 \pm 3.4$ & $29.7 \pm 3.1$ & NS \\
\hline BPs mmHg & $111.0 \pm 8.0$ & $118.2 \pm 7.7$ & NS \\
\hline $\mathrm{BPd} \mathbf{m m H g}$ & $74.5 \pm 3.3$ & $78.4 \pm 4.2$ & NS \\
\hline HR beats $\min ^{-1}$ & $78.3 \pm 8.1$ & $79.5 \pm 10.0$ & NS \\
\hline AHI per hour & $3.2 \pm 1.6$ & $42.4 \pm 17.6$ & $<0.0001$ \\
\hline DI per hour & $9.6 \pm 4.7$ & $31.5 \pm 17.1$ & $<0.0001$ \\
\hline Min. Sa, $\mathrm{O}_{2} \%$ & $84.8 \pm 5.7$ & $73.9 \pm 13.8$ & $<0.0001$ \\
\hline Average $\mathrm{Sa}, \mathrm{O}_{2} \%$ & $94.1 \pm 3.2$ & $80.1 \pm 9.0$ & $<0.0001$ \\
\hline $\begin{array}{l}\text { Sleep duration } \\
\mathrm{Sa}, \mathrm{O}_{2}<\mathbf{9 0} \% \%\end{array}$ & 1.5 & 53.6 & $<0.0001$ \\
\hline QTed ms & $36.3 \pm 4.5$ & $56.1 \pm 9.3$ & $<0.001$ \\
\hline \multicolumn{4}{|c|}{$\begin{array}{l}\text { Data are presented as } \mathrm{n}(\%) \text { or mean } \pm \mathrm{SD} \text {, unless otherwise stated. } \mathrm{AHI} \text { : } \\
\text { apnoea-hypopnoea index; } \mathrm{BMI} \text { : body mass index; } \mathrm{BPs} \text { : systolic blood } \\
\text { pressure; } \mathrm{BPd} \text { : diastolic blood pressure; HR: heart rate; DI: desaturation index; } \\
\text { min.: minimum; } \mathrm{Sa}, \mathrm{O}_{2} \text { : nocturnal arterial oxygen saturation. \#: using the Mann- } \\
\text { Whitney U-test. NS: nonsignificant. }\end{array}$} \\
\hline
\end{tabular}

without hypertension is shown in figure 1 . In addition, a significant positive correlation was shown between QTcd and DI $(\mathrm{r}=0.485, \mathrm{p}<0.01)$. However, statistically negative correlations were found between QTcd and minimum nocturnal $\mathrm{Sa}_{2} \mathrm{O}_{2}$ $(\mathrm{r}=-0.494, \mathrm{p}<0.05)$ and average nocturnal $\mathrm{Sa}_{\mathrm{a}} \mathrm{O}_{2} \quad(\mathrm{r}=-0.452$, $\mathrm{p}<0.05)$.

In OSAS patients, multiple regression analysis was performed to evaluate the relationships described previously when the

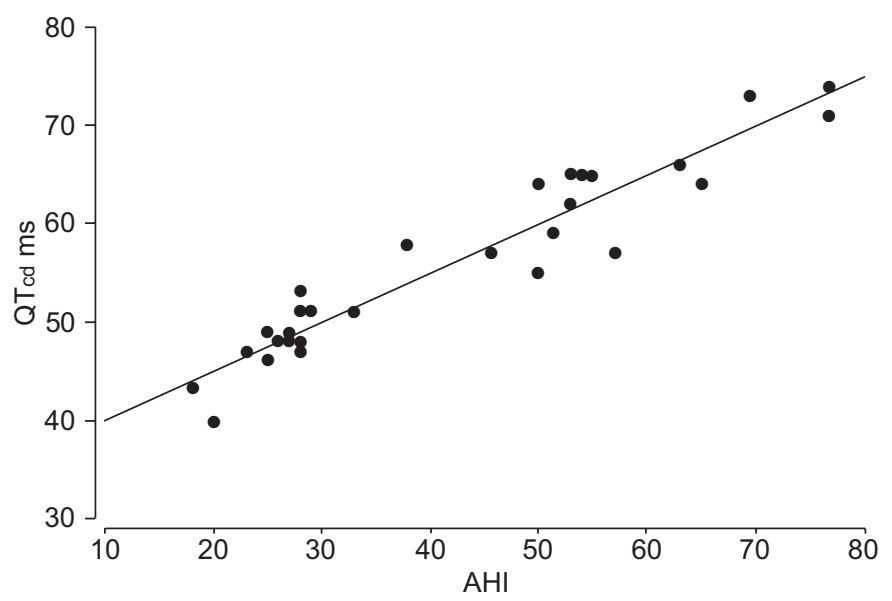

FIGURE 1. Correlation between QT-corrected interval dispersion (QTcd) and apnoea-hypopnoea index (AHI) in obstructive sleep apnoea patients without hypertension. $\mathrm{R}=0.954 ; \mathrm{p}<0.01$. effects of confounding factors such as age, BMI, HR, BPs and $\mathrm{BPd}$ were taken into account, although all of these factors were not significantly different between moderate-severe OSAS patients and controls. The AHI $\left(\mathrm{R}^{2}=0.25, \mathrm{p}=0.0001\right)$, DI $\left(\mathrm{R}^{2}=0.22, \mathrm{p}=0.0001\right)$, minimum and average nocturnal $\mathrm{Sa}_{\mathrm{a}} \mathrm{O}_{2}$ (\%; $\mathrm{R}^{2}=-0.20, \mathrm{p}=0.002$ and $\mathrm{R}^{2}=-0.18, \mathrm{p}=0.002$, respectively) were significantly related to the QTcd as independent variables using stepwise regression analysis.

\section{DISCUSSION}

QTd has been shown to be a useful noninvasive method for the detection of inhomogeneity of ventricular recovery times [1, 2]. In addition, experimental studies provide powerful evidence for the significance of the dispersion of myocardial recovery times in respect to the occurrence of ventricular arrhythmias $[20,21]$. However, there are some problems when trying to achieve an accurate measurement of the QT interval [22]: low $\mathrm{T}$-wave amplitude and the presence of the U-wave create difficulties in identifying the end of the T-wave. Careful selection of the leads from which the T-wave can reliably be identified is required.

It has been proposed that the inter-lead differences in ventricular recovery time could be due to technical artefacts, such as differential tissue attenuation or differences in unipolar versus bipolar leads. DAY et al. [23] have suggested that the QTd could be affected by the number of measurable leads. In the current study, it was found that the number of evaluable leads was, on average, 10 .

Recovery time dispersion has been studied using both invasive and time-consuming methods, such as monophasic action potentials [24] or body surface mapping [25], respectively. QTcd is preferable to QTd when simultaneous 12-lead recording is not available, and inter-lead variations in cycle length could introduce errors in calculation.

The current authors have previously used Bazett's formula [19] for calculation of QTc. To evaluate and compare QTc formulae in 21 healthy subjects, Molnar et al. [26] used 24-h Holter monitoring, as it allows the assessment of QT intervals over a large range of rates. QT-RR relationships for individuals and the group were fitted by regression analysis to five QT prediction formulas: simple Bazett's, modified Bazett's, linear (Framingham), modified Fridericia's and exponential (Sarma's). It was shown that there were no significant differences in mean squared residuals between formulae. When using individually calculated regression parameters, each formula gave good or acceptable QTc over the entire range of RR intervals. The simple Bazett's formula, which uses no regression parameters, was unreliable at high rates. When group-based regression parameters were applied to individuals, no formula had a clear advantage over simple Bazett's. It was concluded that any formula that invokes regression parameters unique to each individual provides satisfactory QTc. When individual parameters cannot be determined, as in a 12-lead ECG, no formula provides an advantage over the familiar simple Bazett's.

The present study showed that QTcd is increased in patients with moderate-severe OSAS when compared with controls. In 
previous studies, QTd has been shown to be increased in patients after acute myocardial infarction [3], and in patients with chronic heart failure [4], long QT syndrome [27] and hypertrophic cardiomyopathy [28].

OSAS is closely associated with obesity [29] and ageing [30]. A strong relationship between systemic hypertension and OSAS has been indicated in some epidemiological studies [10, 11, 3133] and, presently, sleep apnoea is accepted as one of the identifiable causes of hypertension, as shown in the JNC 7 report [13]. It is well known that the risk of developing systemic hypertension increases depending on the severity of OSAS [34]. In addition, strong relationships have been established between the severity of systemic hypertension and AHI, DI and minimum nocturnal $\mathrm{Sa}_{1} \mathrm{O}_{2}$ in several studies $[33,35]$. In addition, it has been suggested that blood pressure decreases when the treatment of OSAS is optimal [36]. In the current study, the proportion of sleep time where $\mathrm{Sa}_{1} \mathrm{O}_{2}$ was $<90 \%$ was highest in the OSAS patients, whereas it was the lowest in the controls. Therefore, the moderate-severe OSAS patients had longer periods of hypoxia during sleep than control subjects. In the present study, the presence of systemic hypertension, diabetes mellitus and coronary artery disease in patients was excluded, and there were no significant differences in sex, age, BMI and arterial blood pressure between subjects. Thus, the QTcd was assessed in uncomplicated (isolated) patients with OSAS. In addition, positive correlations were found between QTcd, and AHI and DI, reflecting the severity of OSAS $(r=0.954, p<0.001$ and $r=0.485, p<0.01$, respectively). AHI $\left(R^{2}=0.25, p=0.0001\right)$ and DI $\left(R^{2}=0.22\right.$, $\mathrm{p}=0.0001$ ) were also significantly related to the QTcd, as independent variables, using stepwise regression analysis. However, there were statistically negative correlations between $\mathrm{QT}_{\mathrm{cd}}$, and minimum and average nocturnal $\mathrm{Sa}_{2} \mathrm{O}_{2}$ ( $\mathrm{r}=-0.494, \mathrm{p}<0.05$ and $\mathrm{r}=-0.452, \mathrm{p}<0.05$, respectively) as expected. Therefore, it might be suggested that increased QTcd in OSAS patients is related to the severity of OSAS and, thus, to hypoxaemia.

Although arrhythmic susceptibility was not assessed in the patients with OSAS, the present observations suggest that degree of AHI is significantly associated with increased inhomogeneity in repolarisation $(\mathrm{r}=0.954, \mathrm{p}<0.001)$, probably predisposing the patients to life-threatening arrhythmias. Several studies have investigated the prevalence of nocturnal arrhythmias in patients with OSAS [6, 37, 38]. Two were prospective studies, which followed-up consecutive referrals and included a control group: the prevalence of arrhythmias in these prospective studies was similar to that observed in healthy adults [37, 38]. The study with the most valid measurement and classification of arrhythmias found no difference between the groups [37].

In this study, the reasons for increased QTcd in patients with OSAS compared with controls have not been clarified. Altered autonomic cardiac control is known to predispose individuals to ventricular arrhythmias under several experimental and clinical conditions [39, 40]; increased sympathetic and/or reduced vagal tone may facilitate arrhythmogenesis by a reentrant mechanism, triggered activity and increased automaticity. In the future, this may be confirmed if HR variability in patients with OSAS is investigated in longitudinal studies.

\section{Conclusion}

The present study demonstrates that increased AHI and DI in patients with OSAS may result in inhomogeneity of repolarisation, favouring a propensity towards ventricular tachyarrhythmias. A significant positive correlation was found between repolarisation inhomogeneity $\left(\mathrm{QT}_{\mathrm{cd}}\right)$ and severity of OSAS (AHI). In the future it will be important to establish whether repolarisation inhomogeneity may be corrected by continuous positive airway pressure treatment aimed at reducing upper airway obstruction in patients with OSAS.

\section{Study limitation}

This study is affected by fundamental limitations in the use of QT interval and QT dispersion measurements. For comparison with other studies, the QT interval was corrected for heart rate. It is well known that Bazett's formula is inaccurate at higher heart rates [26]. It overcorrects at faster heart rates and undercorrects at lower heart rates. In addition, there were only a small number of patients in the present study population, which is an important study limitation. Furthermore, the sleep clinic population used here may not reflect the findings in the general community, and the results should be further confirmed with several longitudinal studies.

\section{REFERENCES}

1 Day CP, McComb JM, Campbell RWF. QT dispersion in sinus beats and ventricular extrasystoles in normal hearts. Br Heart J 1992; 67: 39-41.

2 Zabel M, Portnoy S, Franz MR. Electrocardiographic indexes of dispersion of ventricular repolarization: an isolated heart validation study. J Am Coll Cardiol 1995; 25: 746-752.

3 Perkiomaki J, Koistinen MJ, Yli-Mayry S, Huikuri H. Dispersion of the QT interval in patients with and without susceptibility to ventricular tachyarrhythmias after previous myocardial infarction. J Am Coll Cardiol 1995; 26: 174-179.

4 Barr CS, Naas A, Freeman M, Lang CC, Struthers AD. QT dispersion and sudden unexpected death in chronic heart failure. Lancet 1994; 343: 327-329.

5 Guilleminault C, Tilkian A, Dement WC. The sleep apnea syndromes. Ann Rev Med 1976; 27: 465-484.

6 Guilleminault C, Connoly S, Winkle RA. Cardiac arrhythmia and conduction disturbances during sleep in 400 patients with sleep apnea syndrome. Am J Cardiol 1983; 52: 490-494.

7 Hung J, Whitford EG, Parsons RW, Hillman DR. Association of sleep apnoea with myocardial infarction in men. Lancet 1990; 336: 261-264.

8 Malone S, Liu PP, Holloway R, Rutherford R, Xie A, Bradley TD. Obstructive sleep apnea in patients with dilated cardiomyopathy: effects of CPAP. Lancet 1991; 338: 1480-1484.

9 Palomaki H, Partinen M, Erkinjuntti I, Kaste M. Snoring, sleep apnea syndrome and stroke. Neurology 1992; 42: 75-82.

10 Kales A, Bixler EO, Cadieux RJ, et al. Sleep apnoea in a hypertensive population. Lancet 1984; 2: 1005-1008. 
11 Lavie P, Ben Yosef R, Rubin AE. Prevalence of sleep apnea syndrome among patients with essential hypertension. Am Heart J 1984; 108: 373-376.

12 Weitzenblum E, Krieger J, Apprill M, et al. Daytime pulmonary hypertension in patients with obstructive sleep apnea. Am Rev Respir Dis 1988; 138: 345-349.

13 Chobanian AV, Bakris GL, Black HR, et al. National Heart, Lung, and Blood Institute Joint National Committee on Prevention, Detection, Evaluation, and Treatment of High Blood Pressure and National High Blood Pressure Education Program Coordinating Committee. The Seventh Report of the Joint National Committee on Prevention, Detection, Evaluation, and Treatment of High Blood Pressure: the JNC 7 report. JAMA 2003; 289: 25602572.

14 Johns MW. A new method for measuring daytime sleepiness. Sleep 1991; 14: 540-545.

15 Indications for Polysomnography Task Force, American Sleep Disorders Association Standards of Practice Committee. Practice parameters for the indications for polysomnography and related procedures. Sleep 1997; 20: 406-422.

16 Dingli K, Coleman EL, Vennelle M, et al. Evaluation of a portable device for diagnosing the sleep apnoea/hypopnoea syndrome. Eur Respir J 2003; 21: 253-259.

17 American Sleep Disorders Association. The Atlas Task Force: Bonnet M, Carley D, Carskadom M, et al. EEG arousals: scoring rules and examples. Sleep 1994; 15: 173-184.

18 American Academy of Sleep Medicine Task Force. Sleeprelated breathing disorders in adults: recommendations for syndrome definition and measurement techniques in clinical research. Sleep 1999; 22: 667-689.

19 Bazett HC. An analysis of the time-relations of electrocardiograms. Heart 1920; 7: 353-370.

20 Merx W, Yoon MS, Han J. The role of local disparity in conduction and recovery time on ventricular vulnerability to fibrillation. Am Heart J 1977; 94: 603-610.

21 Kuo C-S, Munakata K, Reddy CP, Surawicz B. Characteristics and possible mechanism of ventricular arrhythmia dependent on the dispersion of action potential durations. Circulation 1983; 67: 1356-1367.

22 Glancy JM, Weston PJ, Bhullar HK, Garrat CJ, Woods KL, de Bono DP. Reproducibility and automatic measurement of QT dispersion. Eur Heart J 1996; 17: 1035-1039.

23 Day CP, McComb M, Matthews J, Campbell RW. Reduction in QT dispersion by sotalol following myocardial infarction. Eur Heart J 1991; 12: 423-427.

24 Franz MR, Bargheer K, Rafflenbeul W, Haverich A, Lichtlen PR. Monophasic action potential mapping in human subjects with normal electrocardiograms: direct evidence for the genesis of the T wave. Circulation 1987; 75: 379-386.

25 Sylven JC, Horacek BM, Spencer CA, Klassen GA, Montague TJ. QT interval variability on the body surface. J Electrocardiol 1984; 17: 179-188.
26 Molnar J, Weiss J, Zhang F, Rosenthal JE. Evaluation of five QT correction formulas using a software-assisted method of continuous QT measurement from 24-hour Holter recordings. Am J Cardiol 1996; 78: 920-926.

27 Linker NJ, Colonna P, Kekwick CA, Till J, Camm AJ, Ward DE. Assessment of QT dispersion in symptomatic patients with congenital long QT syndromes. Am J Cardiol 1992; 69: 634-638.

28 Buja G, Miorelli M, Turrini P, Melacini P, Nava A. Comparison of QT dispersion in hypertrophic cardiomyopathy between patients with and without ventricular arrhythmias and sudden death. Am J Cardiol 1993; 72: 973-976.

29 Levinson PD, McGarvey ST, Carlisle CC, Eveloff SE, Herbert PN, Millman RP. Adiposity and cardiovascular risk factors in men with obstructive sleep apnea. Chest 1993; 103: 1336-1342.

30 Ancoli-Israel S, Coy T. Are breathing disturbances in the elderly equivalent to sleep apnea syndrome? Sleep 1994; 17: 77-83.

31 Peppard PE, Young T, Palta M, Skatrud J. Prospective study of the association between sleep-disordered breathing and hypertension. N Engl J Med 2000; 342: 1378-1384.

32 Nieto FJ, Young TB, Lind BK, et al. Association of sleepdisordered breathing, sleep apnea, and hypertension in a large community-based study. Sleep Heart Health Study. JAMA 2000; 283: 1829-1836.

33 Otsuka K. Hypertension and altered cardiovascular variability associated with obstructive sleep apnea. Nippon Rinsho 2000; 58: 1711-1716.

34 Lavie P, Yoffe N, Berger T, Peled R. The relationship between the severity of sleep apnea syndrome and 24-h blood pressure values in patients with obstructive sleep apnea. Chest 1993; 103: 717-721.

35 Podszus T, Mayer J, Penzel T, Peter JH, von Wichert P. Nocturnal hemodynamics in patients with obstructive sleep apnea. Eur J Respir Dis 1986; 69: 435-442.

36 Mayer J, Becker H, Brandenburg U, Penzel T, Peter JH, von Wichert P. Blood pressure and sleep apnea: results of longterm nasal continuous positive airway pressure therapy. Cardiology 1991; 79: 84-92.

37 Flemons WW, Remmers JE, Gillis AM. Sleep apnea and cardiac arrhythmias. Is there a relationship? Am Rev Respir Dis 1993; 148: 618-621.

38 Hoffstein V, Mateika S. Cardiac arrhythmias, snoring and sleep apnea. Chest 1994; 106: 466-471.

39 Valkama JO, Huikuri HV, Koistinen MJ, Yli-Mayry S, Airaksinen KEJ, Myerburg RJ. Relation between heart rate variability and spontaneous and induced ventricular arrhythmias in patients with coronary artery disease. J Am Coll Cardiol 1995; 25: 437-443.

40 Huikuri HV, Valkama JO, Airaksinen KEJ, et al. Frequency domain measures of heart rate variability before the onset of nonsustained and sustained ventricular tachycardia in patients with coronary artery disease. Circulation 1993; 87: 1220-1228. 